The Israeli Journal of Aquaculture - Bamidgeh, IJA_69.2017.1368, 7 pages

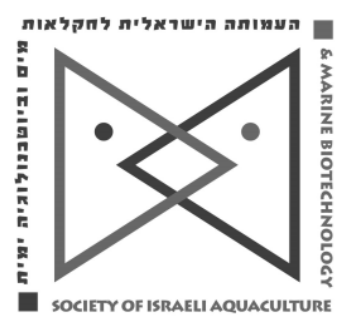

The IJA appears exclusively as a peer-reviewed on-line open-access journal at http://www.siamb.org.il. To read papers free of charge, please register online at registration form.

Sale of $I J A$ papers is strictly forbidden.

\title{
Acinetobacter johnsonii: an Emerging Pathogen for Cultured Blunt Snout Bream Megalobrama amblycephala
}

\author{
Haipeng Cao ${ }^{1,2}$, Linxue $\mathrm{Yu}^{1}$, Renjian $\mathrm{Ou}^{3}$, Liqun $\mathrm{Lu}^{1,2}$, Xianle Yang ${ }^{1}$, \\ Yibin Yang ${ }^{4,5 *}$
}

\footnotetext{
${ }^{1}$ National Pathogen Collection Center for Aquatic Animals, Shanghai Ocean University, Shanghai 201306, P.R. China.

${ }^{2}$ Shanghai University Knowledge Service Platform, Shanghai Ocean University Aquatic Animal Breeding Center (ZF1206), Shanghai 201306, P.R. China.

${ }^{3}$ Longquanyi District Rural Development and Forestry Agency, Chengdu 610100, P.R. China.

${ }^{4}$ Yangtze River Fisheries Research Institute, Chinese Academy of Fishery Sciences, Wuhan 430223, P.R. China.

${ }^{5}$ Freshwater Aquaculture Collaborative Innovation Center of Hubei Province, Wuhan 430070, P.R. China.
}

Keywords: Acinetobacter johnsonii; Megalobrama amblycephala; infection; antibiotic susceptibility.

\begin{abstract}
Bacteriosis has caused significant economic losses in farmed blunt snout bream Megalobrama amblycephala. Only scarce information is available on Acinetobacter johnsonii as a possible causal agent in M. amblycephala. In this study, a virulent strain temporarily named BY3, was isolated from diseased bream, identified phenotypically and molecularly as $A$. johnsonii. Phylogenetic trees of 16S rRNA and gyrB gene sequences were constructed to examine the taxonomic position of isolate BY3 and compare it to other known isolates. When screened against a range of common veterinary antibiotics, isolate BY3 has not shown resistance to florfenicol, neomycin, and sulfisoxazole antibiotics in aquaculture. To the best of our knowledge, this is the first report of $A$. johnsonii infection in farmed blunt snout bream.
\end{abstract}

The first two authors contributed equally to this work.

*Corresponding author: Tel: +862161900453; Fax: +862161900452; Email:

yang19890923@yeah.net. 


\section{Introduction}

Cyprinids are highly important food fish and are widely farmed over a large area of Eurasia. As an emerging industry in China blunt snout bream Megalobrama amblycephala is an important cyprinids fish species for farming. It grows rapidly and is high in economic value (Chen, 2015) with production of over 0.79 million tons in 2015 (Ministry of Agriculture of China, 2016). However, this emerging industry has been seriously affected by bacterial diseases. These should be given more consideration in order to determine the future development and sustainability of this industry. Studies have revealed that Acinetobacter species, particularly Acinetobacter Iwoffii, Acinetobacter baumannii, Acinetobacter junii, cause infections in Clarias fuocus (Li et al., 2001), Ictalurus punctatus (Xia et al., 2008), Carassius auratus gibelio $+\times$ Cyprinus carpio ${ }^{\lambda}$ (Lu et al., 2010) and Acipenser schrenckii (Mao et al., 2013). However, there are few reports on Acinetobacter johnsonii infection in M. amblycephala.

In April 2016, a severe outbreak of the disease occurred in cultured M. amblycephala in outdoor ponds of Xiantao, Hubei province, China. The disease is highly infectious and lethal, causing over $80 \%$ mortality. Diseased fish suffer mainly from symptoms of skin and fin ray hemorrhages. In the present paper, we isolated and identified an Acinetobacter johnsonii pathogen as a causative agent for this disease, and determined its taxonomy and antibiotic susceptibility. To our knowledge, this is the first report of $A$. johnsonii as an emerging pathogen for M. amblycephala.

\section{Materials and methods}

Fish samples. Fifteen diseased M. amblycephala averaging $506 \pm 15 \mathrm{~g}$ were sampled from infected ponds of a fish farm in Xiantao, Hubei China during April 2016. The farm had 56 acres of ponds with juvenile blunt snout bream stocked at an initial rearing density of 1,200 juveniles per acre. The water quality during the disease outbreak was $\mathrm{pH} 7.2,0.12$ $\mathrm{mg} / \mathrm{L}$ total ammonia, $0.03 \mathrm{mg} / \mathrm{L}$ nitrite, and $5.26 \mathrm{mg} / \mathrm{L}$ dissolved oxygen. Diseased samples were placed in sterile bags, kept in ice and transported to the laboratory.

Isolation of the pathogen. Each sampled diseased blunt snout bream was externally disinfected with $75 \%$ alcohol and dissected. Before conducting a careful examination of parasites and viruses using traditional methods as described by Yang \& Yang (2013) and Zeng et al. (2013), samples from spleens, kidneys, and livers of diseased blunt snout bream were streaked onto nutrient brain heart infusion agar (BHIA) plates (Sinopharm Chemical Reagent Co., Ltd.). After incubation for $24 \mathrm{~h}$ at $28^{\circ} \mathrm{C}$, the dominant uniform isolates were purified by streaking and re-streaking onto BHIA plates. Pure isolates of the predominant uniform colonies were stored at $-80^{\circ} \mathrm{C}$ supplemented with $15 \%$ glycerol. A representative of the dominant isolates, temporarily named BY3, was characterized further in the present study.

Identification of the pathogen

Molecular identification. The extraction of genomic DNA from isolate BY3, as well as PCR amplification and sequencing of the 16S rRNA and gyrB genes were performed according to Bing et al. (2010). The near complete 16S rRNA and gyrB gene sequences were assembled using Editseq and Seqman in DNAstar software. Searches were performed in the National Centre for Biotechnology Information (NCBI) database for sequence homology using the Basic Local Alignment Search Tool (BLAST) program. Phylogenetic trees of the near complete 16S rRNA and gyrB gene sequences from the isolate and the homologous sequences were constructed using the neighbor-joining method.

Phenotypic identification. Isolate BY3 was identified phenotypically by API 32E analysis according to our previous study (Cao et al., 2016) where the isolate BY3 was grown on nutrient agar (NA) plates (Sinopharm Chemical Reagent Co., Ltd.) at $28^{\circ} \mathrm{C}$ for $24 \mathrm{~h}$, and the bacterial suspension was then used to inoculate the API 32E test strips (Biomerieux, France) following the manufacturer's instruction. The test strip was incubated at $37^{\circ} \mathrm{C}$ and observed after $18 \mathrm{~h}$ for checking against the API identification index. The type strain ATCC17909 of Acinetobacter johnsonii was used as the control.

Bacterial virulence assay. Bacterial virulence was examined by experimentally infecting healthy blunt snout bream. Fifty healthy fish averaging $100 \pm 10 \mathrm{~g}$ were obtained 
from Baishazhou fishery Co., Ltd. in Wuhan China. Their health status was assessed according to the guidelines in our previous study (Cao et al., 2013). The experimental fish were maintained in five replicate aquaria (ten fish per aquarium) supplied with $50 \mathrm{~L}$ aerated filtered farming water at $20^{\circ} \mathrm{C}$ for 14 days to acclimate. Prior to the bacterial virulence assay, isolate BY3 was inoculated onto NA plate, incubated at $28^{\circ} \mathrm{C}$ for $24 \mathrm{~h}$, and then washed with normal saline into a sterile tube. Its cell density was determined by counting colony forming units after a ten-fold serial dilution in sterile distilled water. Ten healthy fish in each treatment group were challenged by intramuscular injection with 0.2 $\mathrm{mL}$ of isolate BY3 at a concentration of $2.0 \times 10^{4} \mathrm{CFU} / \mathrm{mL}$ to $2.0 \times 10^{7} \mathrm{CFU} / \mathrm{mL}$. Another ten healthy fish exposed to the same experimental conditions were injected intramuscularly $0.2 \mathrm{~mL}$ of normal saline. The experimental fish were kept at $20^{\circ} \mathrm{C}$ and observed daily for seven days without feeding and water change. Any dead fish were immediately removed and sampled to re-isolate and confirm if mortality was caused specifically by the challenge isolate. The mean lethal dose $\left(L_{50}\right)$ value was calculated using the probit analysis as described by Li et al. (2012).

Antibiotic sensitivity assay. The antibiotic sensitivity of isolate BY3 was assayed on NA plates using the Kirby-Bauer disk diffusion method as recommended by Jones et al. (2001). Seventeen antibiotic discs were acquired from Hangzhou Binhe Microorganism Reagent Co., Ltd. The zones of inhibition were measured after a $24 \mathrm{~h}$ incubation period at $28^{\circ} \mathrm{C}$. The antibiotic susceptibility was determined according to the manufacturer's guidelines.

\section{Results}

Pathogen identification. A dominant isolate BY3 was isolated from the diseased farmed $M$. amblycephala and identified by molecular and phenotypic methods as $A$. johnsonii. Its near complete 16S rRNA and gyrB gene sequences were submitted to GenBank database with the accession numbers KY118919 and KY118918. Similarities of $99 \%$ and $97 \%$ are observed in the 16S rRNA and gyrB gene sequences between the BY3 isolate and other $A$. johnsonii isolates from the GenBank database. The phylogenetic trees indicated that the isolate BY3 is an $A$. johnsonii strain (Figures 1 and 2). This was again confirmed by the phenotypic features as $A$. johnsonii (Table 1 ) with $100 \%$ identity compared to the type strain. No parasites and viruses were detected in diseased blunt snout bream from which isolate BY3 was obtained.

Figure 1. A $16 \mathrm{~S}$ rRNA gene tree of 14 known bacteria and the BY3 isolate constructed using the neighborjoining method. The bootstrap values (\%) are shown besides the clades, accession numbers are indicated beside the names of strains, and scale bars represent distance values.

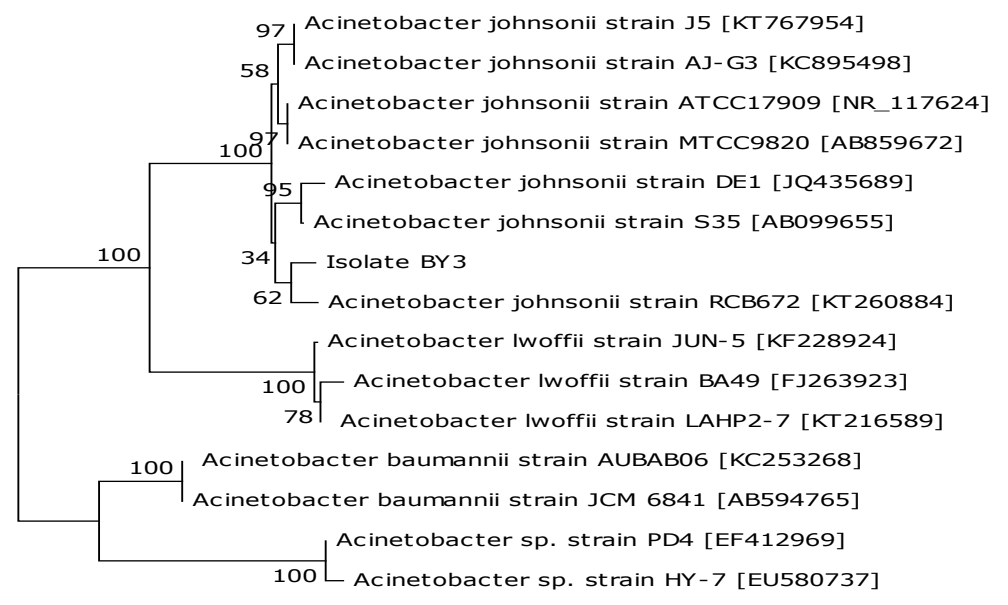

$\stackrel{5005}{0.005}$ 
Figure 2. A gyrB gene tree of 15 known bacteria and the BY3 isolate constructed using the neighbor-joining method. The bootstrap values (\%) are shown besides the clades, accession numbers are indicated beside the names of strains, and scale bars represent distance values.

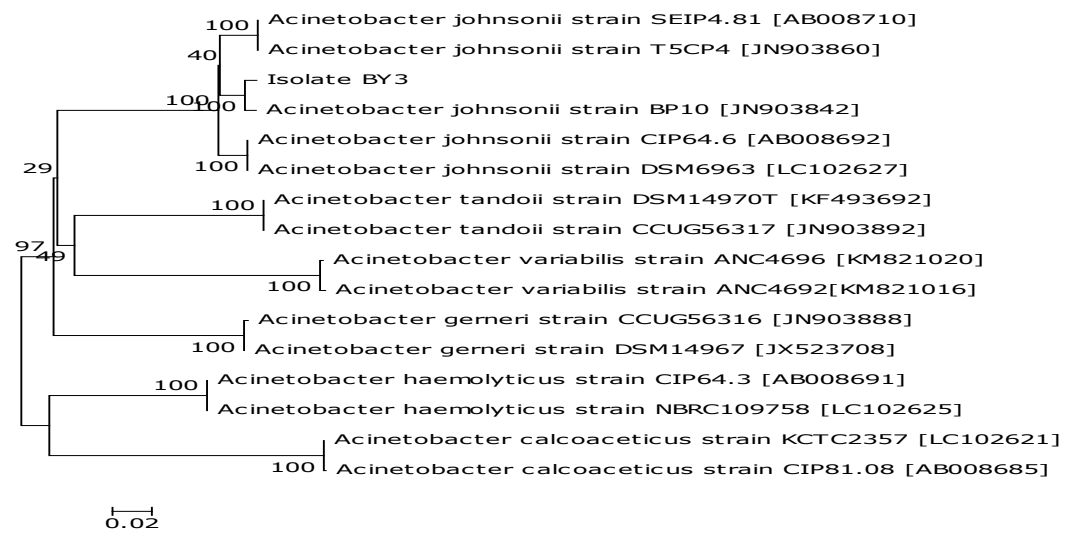

Table 1. Phenotypic characteristics of isolate BY3 in comparison with the type train ATCC17909 of A. johnsonii.

\begin{tabular}{|c|c|c|}
\hline \multirow{2}{*}{ Item } & \multicolumn{2}{|c|}{ Reaction } \\
\hline & BY3 & ATCC17909 \\
\hline Arginine dihydrolase & $\mathrm{R}^{-}$ & $\mathrm{R}^{-}$ \\
\hline Lysine decarboxylase & $\mathrm{R}^{-}$ & $\mathrm{R}^{-}$ \\
\hline Lipase & $\mathrm{R}^{-}$ & $\mathrm{R}^{-}$ \\
\hline L-aspartate aminase & $\mathrm{R}^{+}$ & $\mathrm{R}^{+}$ \\
\hline $\mathrm{N}$-acetyl- $\beta$-glucosaminidase & $\mathrm{R}^{-}$ & $\mathrm{R}^{-}$ \\
\hline a-galactosidase & $\mathrm{R}^{-}$ & $\mathrm{R}^{-}$ \\
\hline a-glucosaccharase & $\mathrm{R}^{-}$ & $\mathrm{R}^{-}$ \\
\hline$\alpha$-maltosidase & $\mathrm{R}^{-}$ & $\mathrm{R}^{-}$ \\
\hline$\underline{\beta}$-galactosidase & $\mathrm{R}^{-}$ & $\mathrm{R}^{-}$ \\
\hline$\beta$-glucosaccharase & $\mathrm{R}^{-}$ & $\mathrm{R}^{-}$ \\
\hline$\underline{\beta}$-glucuronidase & $\mathrm{R}^{-}$ & $\mathrm{R}^{-}$ \\
\hline Urease & $\mathrm{R}^{-}$ & $\mathrm{R}^{-}$ \\
\hline Orinithine decarboxylase & $\mathrm{R}^{-}$ & $\mathrm{R}^{-}$ \\
\hline Indole production & $\mathrm{R}^{-}$ & $\mathrm{R}^{-}$ \\
\hline Malonate utilization & $\mathrm{R}^{-}$ & $\mathrm{R}^{-}$ \\
\hline \multicolumn{3}{|l|}{ Acid production from } \\
\hline Adonitol & $\mathrm{R}^{-}$ & $\mathrm{R}^{-}$ \\
\hline Galacturonic acid & $\mathrm{R}^{-}$ & $\mathrm{R}^{-}$ \\
\hline$\overline{\text { Inositol }}$ & $\mathrm{R}^{-}$ & $\mathrm{R}^{-}$ \\
\hline L-arabinose & $\mathrm{R}^{-}$ & $\mathrm{R}^{-}$ \\
\hline L-arabitol & $\mathrm{R}^{-}$ & $\mathrm{R}^{-}$ \\
\hline L-rhamnose & $\mathrm{R}^{-}$ & $\mathrm{R}^{-}$ \\
\hline D-arabitol & $\mathrm{R}^{-}$ & $\mathrm{R}^{-}$ \\
\hline D-cellobiose & $\mathrm{R}^{-}$ & $\mathrm{R}^{-}$ \\
\hline D-glucose & $\mathrm{R}^{-}$ & $\mathrm{R}^{-}$ \\
\hline D-maltose & $\mathrm{R}^{-}$ & $\mathrm{R}^{-}$ \\
\hline D-mannitol & $\mathrm{R}^{-}$ & $\mathrm{R}^{-}$ \\
\hline$\overline{D-s o r b i t o l}$ & $\mathrm{R}^{-}$ & $\mathrm{R}^{-}$ \\
\hline D-sucrose & $\mathrm{R}^{-}$ & $\mathrm{R}^{-}$ \\
\hline D-trehalose & $\mathrm{R}^{-}$ & $\mathrm{R}^{-}$ \\
\hline 5-ketone-potassium gluconate & $\mathrm{R}^{-}$ & $\mathrm{R}^{-}$ \\
\hline Palatinose & $\mathrm{R}^{-}$ & $\mathrm{R}^{-}$ \\
\hline Sodium pyruvate & $\mathrm{R}^{-}$ & $\mathrm{R}^{-}$ \\
\hline
\end{tabular}

$\mathrm{R}^{+}$: positive reaction; $\mathrm{R}^{-}$: negative reaction.

Isolate BY3 exhibits pathogenicity in an experimental challenge. During the sevenday bacterial virulence experiment, $30 \%-100 \%$ of the experimental fish challenged with isolate BY3 died at a concentration of $2.0 \times 10^{5} \mathrm{CFU} / \mathrm{mL}$ to $2.0 \times 10^{7} \mathrm{CFU} / \mathrm{mL}$ (Table 2) with a $L D_{50}$ value of $6.32 \times 10^{5} \mathrm{CFU} / \mathrm{mL}$ and showed disease signs of skin and fin ray hemorrhages, similar to those seen in the originally diseased fish (Figure 3 ). When challenged with isolate BY3 at a concentration of $2.0 \times 10^{7} \mathrm{CFU} / \mathrm{mL}$, the fish died quickly: 
six fish died on day 1 , three on day 2 , and one on day 3 . Re-isolates from the experimentally diseased fish are identified phenotypically and molecularly as the BY3 isolate. No clinical signs or mortality were noted in the control fish.

Table 2. Experimental infections of M. amblycephala with isolate BY3.

\begin{tabular}{|c|c|c|c|c|c|c|c|c|c|c|}
\hline \multirow{2}{*}{ Group } & \multirow{2}{*}{$\begin{array}{c}\text { Concentration } \\
(\mathrm{CFU} / \mathrm{mL})\end{array}$} & \multirow{2}{*}{$\begin{array}{l}\text { Fish } \\
\text { no. }\end{array}$} & \multicolumn{7}{|c|}{$\begin{array}{l}\text { Dead fish no. on day } \\
\text { after challenge }\end{array}$} & \multirow{2}{*}{$\begin{array}{c}\text { Cumulative mortality } \\
(\%)\end{array}$} \\
\hline & & & 1 & 2 & 3 & 4 & 5 & 6 & 7 & \\
\hline Control & 0 & 10 & 0 & 0 & 0 & 0 & 0 & 0 & 0 & 0 \\
\hline Treated 1 & $2.0 \times 10^{4}$ & 10 & 0 & 0 & 0 & 0 & 0 & 0 & 0 & 0 \\
\hline Treated 2 & $2.0 \times 10^{5}$ & 10 & 1 & 2 & 0 & 0 & 0 & 0 & 0 & 30 \\
\hline Treated 3 & $2.0 \times 10^{6}$ & 10 & 3 & 2 & 2 & 1 & 0 & 0 & 0 & 80 \\
\hline Treated 4 & $2.0 \times 10^{7}$ & 10 & 6 & 3 & 1 & 0 & 0 & 0 & 0 & 100 \\
\hline
\end{tabular}

Figure 3. The pathological symptoms of diseased M. amblycephala. Arrows show skin and fin ray hemorrhages.

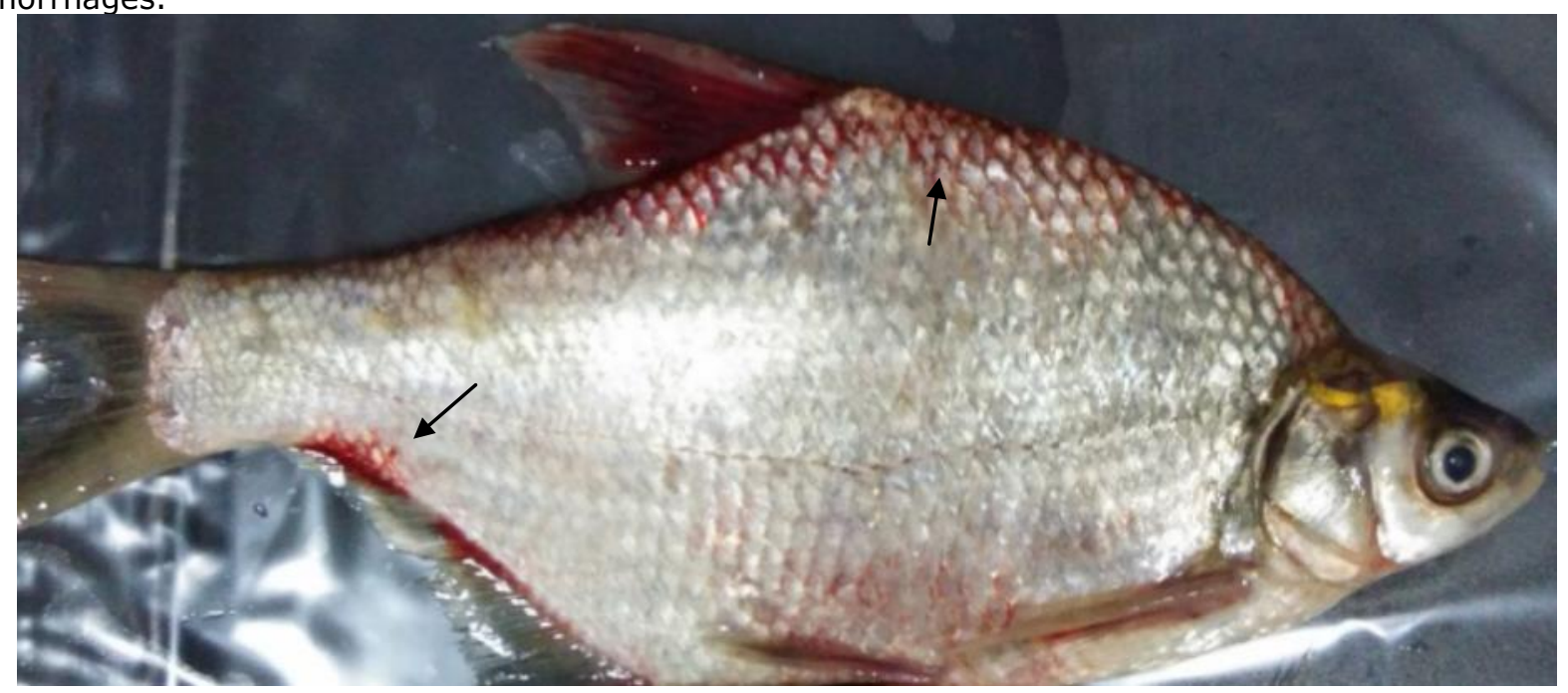

Antibiotic sensitivity. The antibiotic susceptibility of isolate BY3 is shown in Table 3 . The data indicate that isolate BY3 is resistant to clindamycin and oxacillin, and intermediately sensitive or sensitive to the other fifteen tested antibiotics. This suggests that isolate BY3 has not developed resistance to florfenicol, neomycin, and sulfisoxazole antibiotics in aquaculture.

Table 3. Susceptibility of isolate BY3 to antibiotics.

\begin{tabular}{lcc}
\hline Antibiotics & $\begin{array}{c}\text { Content } \\
(\mu \mathrm{g} / \text { disc })\end{array}$ & $\begin{array}{c}\text { Inhibition zone diameter } \\
(\mathrm{mm})\end{array}$ \\
\hline Chloramphenicol & 300 & $22.94 \pm 0.36^{\mathrm{S}}$ \\
Cefotaxime & 30 & $24.86 \pm 0.21^{\mathrm{S}}$ \\
Cefradine & 30 & $23.05 \pm 0.04^{\mathrm{S}}$ \\
Ciprofloxacin & 5 & $29.61 \pm 0.63^{\mathrm{S}}$ \\
Clindamycin & 2 & $0 \pm 0^{\mathrm{R}}$ \\
Doxycycline & 30 & $29.63 \pm 0.27^{\mathrm{S}}$ \\
Erythrocin & 15 & $2.03 \pm 0.10^{\mathrm{I}}$ \\
Florfenicol* & 75 & $28.01 \pm 0.13^{\mathrm{S}}$ \\
Furazolidone & 300 & $13.95 \pm 0.11^{\mathrm{R}}$ \\
Levofloxacin & 5 & $31.87 \pm 0.07^{\mathrm{S}}$ \\
Norfloxacin & 10 & $24.79 \pm 0.17^{\mathrm{S}}$ \\
Neomycin* & 30 & $23.95 \pm 0.13^{\mathrm{S}}$ \\
Oxacillin & 1 & $0 \pm 0^{\mathrm{R}}$ \\
Penicillin & 10 & $20.02 \pm 0.04^{\mathrm{I}}$ \\
Rifampicin & 5 & $21.98 \pm 0.13^{\mathrm{S}}$ \\
Streptomycin & 10 & $21.32 \pm 0.63^{\mathrm{S}}$ \\
Sulfisoxazole & 300 & $29.83 \pm 0.19^{\mathrm{S}}$ \\
\hline
\end{tabular}


Data are presented as the mean \pm standard deviation; ${ }^{S}$ Sensitive; Intermediately sensitive; ${ }^{R}$ Resistant. *Veterinary antibiotics used in aquaculture.

\section{Discussion}

The connection between $A$. johnsonii with cyprinids fish diseases in aquaculture has been little documented. Only isolates of $A$. johnsonii from diseased rainbow trout have been characterized to some extent (Kozinska et al., 2014). Little is known about $A$. johnsonii isolates from diseased farmed blunt snout bream. In this study, we characterized the phenotype, taxonomic position and antibiotic susceptibility of $A$. johnsonii BY3. To our knowledge, this is the first report of an A. johnsonii pathogen as a causative agent for farmed blunt snout bream.

Cultured cyprinids fish are sensitive to $A$. johnsonii infection (Kozinska et al., 2015). In the present study, the BY3 isolate was found to cause mortality in healthy cyprinid fish M. amblycephala with a $\mathrm{LD}_{50}$ value of $6.32 \times 10^{5} \mathrm{CFU} / \mathrm{mL}$. This further demonstrates the potential threat of $A$. johnsonii to cyprinids fish farming. Various virulence factors are involved in the pathogenicity of Acinetobacter, like adherence to epithelial cells, production of extracellular enzymes and toxins, as well as the ability to protect against phagocytosis (Braun, 2008). The pathogenicity of isolate BY3 could probably be associated with the production of these virulent factors. Apart from the virulence of the BY3 isolate, there might be other secondary factors that induce this infection in $M$. amblycephala such as use of contaminated feed and high breeding densities that should be of concern.

Intensive aquaculture has resulted in the use of antimicrobials to retard bacterial infections. The use of antibiotics has caused emergence of antibiotic resistant bacteria. The BY3 isolate in our study is sensitive to florfenicol, neomycin, and sulfisoxazole antibiotics that can be used as potent antimicrobial agents in the treatment of $A$. johnsonii infection in cyprinids fish. However, Acinetobacter strains are commonly known as antibiotic resistance gene transmitters (Kozinska et al., 2014). Isolate BY3 might have a great impact on antibiotic resistance transfer in cyprinids fish farming.

In conclusion, the present study demonstrates $A$. johnsonii as an emerging bacterial pathogen for farmed M. amblycephala. The pathogenicity of the BY3 isolate supports this infection as a potential threat in blunt snout bream farming.

\section{Acknowledgments}

This work has been financially supported by Earmarked Fund for China Agriculture Research System (No. CARS-46) and Minhang District Industry-University-Research Institute Program, Shanghai China (No. 2016MH252).

\section{References}

Bing X., Yan B., Zhang X., Qin L., Bi K., 2009. Phenotypic and molecular identification of pathogenic Vibrio cholerae isolated from Misgurnus anguillicaudatus. Oceanologia et Limnologia Sinica, 40(6):692-698.

Braun G., 2008. Virulence mechanisms of Acinetobacter. pp.145-154. In: E. BergogneBérézin, H. Friedman, M. Bendinelli (eds.). Infect agent pathogenesis. Springer US, New York.

Cao H., Ye W., He S., Li Y., Yang Y., 2016. Acinetobacter Iwoffii: an emerging pathogen for red head disease in farmed channel catfish Ictalurus punctatus., Isr. J. Aquacuult.-Bamidgeh, IJA_68.2016.1325.

Cao H., Zheng W., He S., Ye X., Xiao G., Yang X., 2013. Identification of a Vibrio cholerae isolate as the causal agent of ascites disease in cultured mandarin fish Siniperca chuatsi (Basilewsky)., Isr. J. Aquacult.-Bamidgeh, IJA_65.2013.914.

Chen R.L., 2015. The status and development trends of blunt snout bream industry. Sci Fish Farming, 2: 4-5.

Jones R.N., Ballow C.H., Biedenbach D.J., 2001. Multi-laboratory assessment of the linezolid spectrum of activity using the Kirby-Bauer disk diffusion method: Report of the Zyvox@ antimicrobial potency study (ZAPS) in the United States. Diagn Micr Infec Dis., 40:59-66.

Kozinska A., Pazdziori E., Pekala A., Niemczuk W., 2014. Acinetobacter johnsonii and Acinetobacter Iwoffii-the emerging fish pathogens. B Vet I Pulawy, 58(2): 193-199.

Kozinska A., Pekala A., Grawinski E., 2015. New bacterial infections that have emerged in fish in Poland. Medycyna Weterynaryjan-Veter Med-Sci Pract, 71(9): 548552. 
Li C., Wu M., Wang H., 2012. LC L $_{50}$ calculated by Kochi, probit analysis and linear regression methods. Progress in Veterinary Medicine, 33(9):92-94.

Li G., Li H., Bi Y., 2001. The pathogenic bacteria of the "erecting body" disease in catfish, Clarias fuocus. J Fish Sci China, 8(2):72-75.

Lu W., Chen H., Zou Y., Yang Y., Wang X., Huang C., 2010. Identification and drug sensitive test of the pathogen in Acinetobacter disease from hybrid crucian carp Carassius auratus gibelio 9 × Cyprinus carpio ${ }^{\lambda}$. Fish Sci., 29(3): 156-161.

Mao Z., Mao Y., Wang J., 2013. Isolation, identification and drug-resistance genes detection of Acinetobacter junii from fish. J Fish China, 37(10):1572-1578.

Ministry of Agriculture of China, 2016. China Fishery Statistical Yearbook. Beijing: China Agriculture Press, pp31.

Xia L., Xiong D., Gu Z., Xu Z., Chen C., Xie J., Xu P., 2008. Recovery of Acinetobacter baumannii from diseased channel catfish (Ictalurus punctatus). Aquaculture, 284: 285288.

Yang S., Yang Z., 2013. Preliminary studies on diagnosis, prevention and treatment of parasitic diseases in ornamental fishes. Chinese J Anim Infect Dis., 21(5):57-62.

Zeng W., Wang Q., Wang Y., Liu C., Tan A., Shi C., Wu S., 2013. Isolation and characterization of a rhabdovirus from snakehead fish (Ophicephalus striatus). J Fish China, 37(9): 1416-1424. 